East African Medical Journal Vol. 77 No. 11 November 2000

EYE DISEASES AND BLINDNESS IN ADJUMANI REFUGEE SETTLEMENT CAMPS, UGANDA

M. Kawuma, MBChB, MRC Ophth, MD, Associate Professor, Department of Ophthalmology, Makerere University Medical School, P.O. Box 7072, Kampala, Uganda.

\title{
EYE DISEASES AND BLINDNESS IN ADJUMANI REFUGEE SETTLEMENT CAMPS, UGANDA
}

\author{
M. KAWUMA
}

\begin{abstract}
Objectives: To determine the prevalence and causes of the blindness and ocular morbidity amongst Sudanese refugees; to prioritise and provide eye care services to the refugees and; to device administrative strategies and logistics of prevention and control of blinding diseases among the refugees.

Design: A mobile outreach clinic study for six weeks.

Setting: Adjumani settlement camps for Sudanese refugees in Uganda.

Participants: Seven hundred patients in eighteen settlement camps.

Interventions: Medical treatment and surgical correction offered.

Main outcome measures: Cataract, trachoma and xerophthalmia are the major causes of blindness.

Results: One hundred and forty six patients (21\%) were bilaterally blind, and 77 patients $(11 \%)$ were unilaterally blind. The three leading causes of blindness are cataract $(42 \%)$, xerophthalmia $(28 \%)$ and trachoma $(21 \%)$. Glaucoma and other non-specified causes were responsible for the remaining blindness $(9 \%)$. The crude prevalence of blindness among the 700 patients was 20 . This is an extremely high prevalence, nearly ten times higher than for Ugandans living in Uganda. Conclusion: In refugee settlement camps setting, residents may have a much higher prevalence of eye diseases and blindness than non-refugees.
\end{abstract}

\section{INTRODUCTION}

Blindness is a worldwide major health problem(1). The causes of blindness and the pattern of eye diseases differ in developing and developed countries and often in communities (2-9). In developing countries and in various communities, cataract, corneal opacities and glaucoma are the major causes of blindness(10-14).

Uganda has few ophthalmologists. Most of them are based at Makerere University Medical School or in other settings in the capital city, Kampala. Most regions do not enjoy the services of an ophthalmologist. Eye care in other regions is provided by clinical assistants and nurses.

Adjumani district is in the northern region of Uganda, and borders southern Sudan. In the whole district there is only one ophthalmic paramedical working from Adjumani Hospital. He is a Government employee, and ordinary refugees in settlement camps have no access to him. Between January and February 1999, Africa Humanitarian Action hired an ophthalmologist to travel to individual settlement camp health units. Working in such underserved and unserved environment, the ophalmologist carried out this study to provide eye care to the refugees, determine the prevalence, and causes of blindness among Sudanese refugees in Uganda and to device methods and administrative strategies to tackle the problem of blindness among the refugees.

\section{MATERIALS AND METHODS}

Mobile outreach eye clinics were conducted in the settlement camps during the months of January and February 1999 for the purpose of identifying the prevalence of eye diseases and providing eye care to the camps population. The study was done in 18 out of the 25 settlement camps. Before the clinics were carried out, the respective health care workers and leaders in the health units serving the various settlement camps were informed in good time. Patients requiring eye care were informed and assembled in areas where clinics were to be held. The patients were registered and the ocular history taken. The visual acuity of each eye was charted using the Snellen or E chart, for literate and illiterate patients respectively. Categories of visual loss were recorded according to the World Health Organisation definitions.

The anterior segment was examined with a torch and loupe. Abnormalities detected were documented. The posterior segment was examined by a direct ophthalmoscope with pupils dilated, if found necessary. Intraocular pressures were taken using Schoitz tonometer.

\section{RESULTS}

Seven hundred eye patients were seen. The attendance was low in some camps and high in others, for example, in both Maaji B and Maaji C and in Mirieyi, the attendance was poor, whereas in Alere, Mongula and Keyo the attendance was good. Table 1 shows the age distribution of the study population. Patients under fifteen years, 
comprised only seven per cent of the study group despite their known big numbers in the community. Those over 76 years were few. Thirty people, all adults, did not state their age because they did not know how old they were. One hundred and forty six patients $(21 \%)$ of all patients examined were blind in both eyes. Seventy seven patients $(11 \%)$ were unilaterally blind. One hundred and twelve patients ( $16 \%$ ) had significant diminution of vision (VA of between (6/24 and 6/60).

Table 1

Age distribution of the study population

\begin{tabular}{lrc}
\hline Age group & No. & $\%$ \\
\hline $0-15$ & 50 & 7 \\
$16-30$ & 180 & 26 \\
$31-45$ & 230 & 33 \\
$46-60$ & 175 & 25 \\
$61-75$ & 21 & 3 \\
$76+$ & 14 & 2 \\
Age unknown & 30 & 4 \\
\hline Total & 700 & 100 \\
\hline
\end{tabular}

The causes of blindness in the population is shown in Table 2. The leading blinding eye diseases in the study population were cataract, vitamin A deficiency (xerophthalmia) and trachoma.

Table 2

Causes of blindness

\begin{tabular}{lcc}
\hline Disease & No. & $\%$ \\
\hline Cataract & 60 & 42 \\
Xerophthalmia & 41 & 28 \\
Trachoma & 30 & 21 \\
Glaucoma & 6 & 4 \\
Others & 9 & 5 \\
\hline Total & 146 & 100 \\
\hline
\end{tabular}

Out of 700 patients who were examined, $35 \%$ were women and $65 \%$ men. The crude prevalence of blindness among the 700 people examined (best visual acuity $<3 / 60$ was $20 \%$. This is an extremely high prevalence. The leading non-blinding eye diseases or conditions were presbyopia (age - related reading difficulties), conjunctivitis, and vernal catarrh in children.

As many as 76 middle - aged men and women had marked presbyopia, and could not read ordinary - sized print without reading glasses. Immature cataracts and trachoma sequalae accounted for over $90 \%$ of significantly reduced visual acuity.

\section{DISCUSSION}

Results from mobile eye clinics do not provide exact information on the prevalence of eye diseases in the community under study. However, the data obtained is of great importance in the planning of eye services in these areas. Screening for eye diseases is important in identifying those patients at risk of getting blind and providing the right treatment to them. Screening for diseases in refugee camps in developing countries is almost unheard of due to a number of factors, among them the cost of screening and lack of manpower.

Ophthalmologists are the most important cadre of health workers to screen for eye diseases but they are too few, and many loathe the idea of working for weeks or months in insecure refugee settlement camps, away from their families. The attendance of men and women was in the ratio of $2: 1$. This is in agreement with the general observation that fewer females are seen in medical clinics than males in the developing countries. Nearly eleven per cent of the 76 patients examined had difficulty in reading which was agerelated. All of them could read normally when they were made to wear trial reading glasses. Cataract was the major cause of blindness. This supports the findings of previous reports $(8,10)$ that cataract is the major blinding disease. Cataract is a major eye problem in the refugee camps which needs to be addressed properly. Forty two per cent of all blindness was due to cataract alone. Vitamin A deficiency disorders (xerophthalmia) was the second commonest cause of blindness. Unfortunately, most of this type of blindness was observed among children less than ten years old. Most of them had dense corneal opacities or bilaterally perforated eyes. The third commonest cause of blindness was trachoma. This was due to dense, bilateral corneal opacities resulting from lashes rubbing on the cornea, and entropion. Primary open angle glaucoma and other diseases such as optic atrophy, trauma, maculopathies and retinitis pigmentosa together accounted for ten per cent of the total blindness.

In their study of causes of blindness in Uganda Kawuma and Serunjogi recorded blindness as being due to disease of the cornea, lens, uvea, retina (and optic nerve) or whole eye, and glaucoma was given a classification of its own separate from the retina and optic nerve(15). The blindness prevalence rate in Uganda is 2.3. A survey in central rural Tanzania in 1978 gave a blindness prevalence of 2.3(16). The overall rate of blindness prevalence for most rural areas in Africa is somewhere between 1-3(17). Cataract is the leading cause of blindness in Uganda, accounting for $41 \%$ of all blindness. Among the Sudanese refugees cataract accounted for $42 \%$ of the blindness. Corneal scarring (from trachoma and xerophthalmia) accounts for $35 \%$ of the blindness in Uganda. Among the Sudanese refugees the corresponding figure is $49 \%$. The third commonest cause of blindness in Uganda is glaucoma which causes six per cent of the blindness. Among the Sudanese refugees glaucoma is responsible for four per cent of the blindness.

The three leading causes of blindness among Sudanese 
refugees living in Uganda are cataract, xerophthalmia and trachoma. The three accounted for $91 \%$ of all the blindness. Efforts by international organisations may go a long way in reducing the high prevalence of blindness among Sudanese refugees. This is possible because cataract is treatable, and both xerophthalmia and trachoma are preventable. The prevalence of the blinding eye diseases in Adjumani Refugee Settlement Camps necessitates that immediate action be taken by the UNHCR and other wellwishing international organisations, while longer term programme activities are planned and eventually implemented. Suggested immediate short-term interventions are:(i) provide adequate supply of tetracycline or chloramphenicol eye ointment to every health centre in the refugee camps. All children presenting to any clinic with red, discharging or crusty eyes should be given a tube of ointment; (ii) provide an adequate supply of vitamin A capsules to every health clinic. All children below the age of six years presenting to any clinic should be dosed with 200,000 international units. This should be repeated every after six months till the child is over six years of age and; (iii) provide regular, periodic mobile surgical ophthalmic services for cataract and entropian to Adjuman Refugee Settlement Camps.

Recommendations for long-term interventions should include: (i) re-educating the refugees that blindness due to cataract is treatable and curable; (ii) re-training of the primary health care workers in the settlement camps in recognising and treating active trachoma, especially in young children and; (iii) conducting further studies to identify appropriate intervention strategies to be used to reduce the high prevalence and severity of inflammatory trachoma in young children through cost-effective environmental manipulation.

\section{REFERENCES}

1. World Health Organisation: Data on blindness throughout the world. Wld. Hlth. Org. Chron. 1979; 33:275-279.
2. Kayembe L. Common causes of blindness in Zaire. Brit. J. Ophthal. 1985; 69:339-340.

3. Ghafour I. M, Allan D. and foulds W.S. Common causes of blindness and visual handicap in the West of Scotland. Brit J. Ophthal 1983; 67:209-211.

4. Mansour A. M., Kassak K. Cl-aya M., Hourani T., Sibai A. and Alameddine M.N. National survey of blindness and low vision in Lebanon. Brit. J. Ophthol. 1997; 81:905-908.

5. Taylor H.R., Livingstone P. M., Stanislansky Y.L., and McCarty C. Visual impairement in Australia: Distance visual acuity, near vision and field findings of the melbourne Visual impairement project. Amer. J. Ophthal 1997; 123:328-331.

6. Negrel A. D., Minassia D.C, and Sayek F. Blindness and low vision in south East Turkey. Opthalmic Epidemiology 1996; 3:127-129.

7. Newland H.S., Hiller J.E. and Obermeder S. Prevalence and causes of blindness in South Australia population aged 60 and over. Ophthal. Epidem. 1996; 3:97-99.

8. Adeoye A. Survey of blindness in rural communities of South Western Nigeria. Trop. Med Jut Hlth. 1996; 1:72-75.

9. Kotland C., Koster J. C., Coulibaly S. and Dubbeladam R.P. Prevalence of blindness and visual impairement in the region of Segon, Male. A baseline survey for primary eye care programme. Trop. Med. Int. Hlth. 1996; 1:314-317.

10. Sangawe, J.L.F. Causes of blindness as seen at Muhimbili Medical centre, Dar es Salaam, Tanzania. East Afr. Med. J. 1998; 65:314316.

11. Ezepue U.F. Magnitude and causes of blindness and low vision in Anambra state of Nigeria. Publ. Hlth. 1997; 11:305-307.

12. Zerihun N., and Nebey D. Blindness and low vision in Jimma Zone, Ethiopia. Ophthal. Epidem. 1997; 4:19.

13. Wilson M.R., Mansour M., Ross-Degnan D., Moukouri E., Fobi G. Alemayehu W., Martone J.F., Casey R. and Bazargon M. Prevalence and causes of low vision and blindness in the extreme North Province of Cameroon, West Africa. Ophthal. Epidem. 1996; 3:23-25.

14. Alemayahu W., Tekle - Haimanot R. Forsgren L. and Erkestede J. Cause of visual impairment in central Ethiopia. Ethiop. Med. J. 1995; 33:163-165.

15. Kawuma M., Serunjogi L. Kamuli Blindness and Vitamin a Deficiency Survey Report, Ministry of Health, Technical Report Series 1, Number 1, 1992.

16. Foster, A. Prevalence of Blindness in Central Tanzania, unpublished data.

17. Goldstein, H. The Reported Demography and causes of Blindness throughout the world. Adv. Ophthalmol. 1980; 40:140-145. 